PREPARED FOR THE U.S. DEPARTMENT OF ENERGY, UNDER CONTRACT DE-AC02-76CH03073

PPPL-3576

PPPL-3576

UC-70

\title{
High-Harmonic Fast-Wave Heating in NSTX
}

B.P. LeBlanc, R.E. Bell, P.T. Bonoli, J.C. Hosea, D.W. Johnson, T.K. Mau, J. Menard, D. Mueller, M. Ono, F. Paoletti, S. Paul, C.K. Phillips, R. Pinsker, A. Rosenberg, P.M. Ryan, S.A. Sabbagh, D. Stutman, D.W. Swain, Y. Takase, J.B. Wilgen, and J.R. Wilson

June 2001
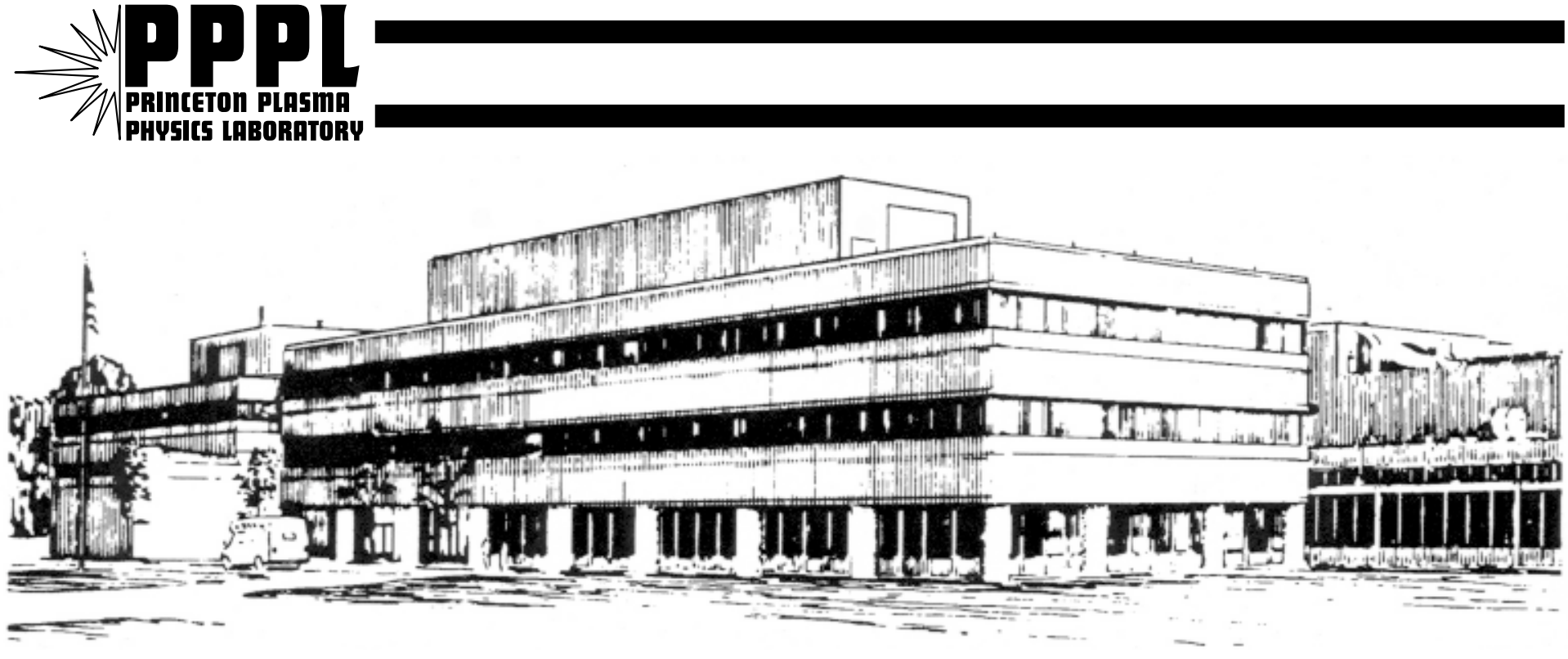

PRINCETON PLASMA PHYSICS LABORATORY PRINCETON UNIVERSITY, PRINCETON, NEW JERSEY 


\section{PPPL Reports Disclaimer}

This report was prepared as an account of work sponsored by an agency of the United States Government. Neither the United States Government nor any agency thereof, nor any of their employees, makes any warranty, express or implied, or assumes any legal liability or responsibility for the accuracy, completeness, or usefulness of any information, apparatus, product, or process disclosed, or represents that its use would not infringe privately owned rights. Reference herein to any specific commercial product, process, or service by trade name, trademark, manufacturer, or otherwise, does not necessarily constitute or imply its endorsement, recommendation, or favoring by the United States Government or any agency thereof. The views and opinions of authors expressed herein do not necessarily state or reflect those of the United States Government or any agency thereof.

\section{Availability}

This report is posted on the U.S. Department of Energy's Princeton Plasma Physics Laboratory Publications and Reports web site in Calendar Year 2001. The home page for PPPL Reports and Publications is: http://www.pppl.gov/pub_report/

DOE and DOE Contractors can obtain copies of this report from:

U.S. Department of Energy

Office of Scientific and Technical Information

DOE Technical Information Services (DTIS)

P.O. Box 62

Oak Ridge, TN 37831

Telephone: (865) 576-8401

Fax: (865) 576-5728

Email: reports@adonis.osti.gov

This report is available to the general public from:

National Technical Information Service

U.S. Department of Commerce

5285 Port Royal Road

Springfield, VA 22161

Telephone: 1-800-553-6847 or

(703) 605-6000

Fax: (703) 321-8547

Internet: http://www.ntis.gov/ordering.htm 


\title{
High-Harmonic Fast-Wave Heating in NSTX*
}

B.P. LeBlanc ${ }^{\text {a }}$, R.E. Bell ${ }^{\text {a }}$ P.T. Bonoli ${ }^{\text {h }}$, J.C. Hosea ${ }^{a}$, D.W. Johnson ${ }^{\text {a }}$, T.K. Mau ${ }^{\mathrm{f}}$, J. Menard ${ }^{\mathrm{a}}$, D. Mueller ${ }^{\mathrm{a}}$, M. Ono ${ }^{\mathrm{a}}$, F. Paoletti ${ }^{\mathrm{e}}$, S. Paul ${ }^{\mathrm{a}}$, C.K. Phillips ${ }^{\mathrm{a}}$, R. Pinsker ${ }^{\mathrm{d}}$, A. Rosenberga , P.M. Ryan' ${ }^{\mathrm{c}}$, S.A. Sabbagh ${ }^{\mathrm{e}}$, D. Stutman ${ }^{\mathrm{b}}$, D.W. Swain ${ }^{\mathrm{c}}$, Y. Takase ${ }^{\mathrm{g}}$, J.B. Wilgen ${ }^{\mathrm{c}}$, J.R. Wilson ${ }^{\mathrm{a}}$

${ }^{a}$ Princeton Plasma Physics Laboratory, Princeton, New Jersey, 08543

${ }^{b}$ Johns Hopkins University, Batimore, Maryland

${ }^{c}$ Oak Ridge National Laboratory, Oak Ridge, Tennessee

${ }^{d}$ General Atomics, La Jolla, California

${ }^{e}$ Columbia University, New York, New York

${ }^{f}$ UCSD, San Diego, California

${ }^{8}$ University of Tokyo, Tokyo, Japan

${ }^{h}$ MIT, Cambridge, $M A$

\begin{abstract}
High-Harmonic Fast-Wave (HHFW), a radio-frequency technique scenario applicable to high-beta plasmas, has been selected as one of the main auxiliary heating systems on NSTX. The HHFW antenna assembly comprises 12 toroidally adjacent current elements, extending poloidally and centered on the equatorial plane. This paper reviews experimental results obtained with a symmetrical (vacuum) launching spectrum with $k_{/ /}=14 \mathrm{~m}^{-1}$ at a frequency of 30 MHz. We describe results obtained when HHFW power is applied to helium and deuterium plasmas, during the plasma-current flattop period of the discharge. Application of 1.8-MW HHFW pulse to MHD quiescent plasmas resulted in strong electron heating, during which the central electron temperature, $T_{e o}$ more than doubled from $\approx 0.5 \mathrm{keV}$ to $1.15 \mathrm{keV}$. In deuterium plasmas, HHFW heating was found less efficient, with a $T_{e 0}$ increase of the order of $40 \%$ during a $1.8-\mathrm{MW}$ $\mathrm{HHFW}$ pulse, from $\approx 400 \mathrm{eV}$ to $\approx 550 \mathrm{eV}$. (At HHFW power of $2.4 \mathrm{MW}, T_{e o}$ increased by $60 \%$, reaching $0.625 \mathrm{keV}$.) HHFW heating in presence of MHD activity is also discussed. A short neutral beam pulse was applied to permit charge-exchange recombination spectroscopy (CHERS) measurement of the impurity ion temperature $T_{i}$. Preliminary CHERS analysis show that $T_{i} \approx T_{e}$ during HHFW heating. Of special interest are deuterium discharges, where the application of HHFW power was done during the current ramp-up. We observe the creation of large density gradients in the edge region. In the latter case, the density rose spontaneously to $n_{e o} \leq 8 \times 10^{13} \mathrm{~cm}^{-}$
\end{abstract}

\section{INTRODUCTION}

The coming on line of the NSTX spherical torus (ST) device has enabled exploration of new regimes of magnetically confined plasmas, with the toroidal field lower than in the "usual" tokamak by an order of magnitude. NSTX has already demonstrated temperatures in the 1-2 keV range, densities in the upper $10^{13} \mathrm{~cm}^{-3}$, and magnetically derived beta toroidal values up to $21 \%$ [1]. Such parameters entail wave physics phenomena with values of the dielectric constant $\varepsilon \equiv \omega_{p e}{ }^{2} / \Omega_{\varepsilon}{ }^{2} \approx 50-100$, which

${ }^{*}$ This work was supported at PPPL by DOE Contract DEAC02-76CH03073 
are large compared to conventional tokamak plasmas, where $\varepsilon \approx 1$. For such high $\varepsilon$-value plasmas, an attractive fast-wave window opens in the high harmonic frequency range, $\Omega_{i}<<\omega<<\omega_{L H}$, which permits electron heating and current drive [2]. Auxiliary heating using these high-harmonic fast waves (HHFW) has been selected as a core element of the NSTX research program. While prior HHFW heating demonstration was done on the CDX-U [3], NSTX is the first ST of its size - plasma volume $\approx 10 \mathrm{~m}^{3}-$ to make use of HHFW.

In this paper, we give a short description of the HHFW heating implementation on NSTX, then follow with the description of experimental data. We begin by discussing two heating experiments performed during the flattop of the plasma current $I_{p}$. Temperature increase without fuelling is observed in the first case, while density evolution effects are also observed in the second case. We then follow with the description of HHFW heating during the $I_{p}$ ramp-up phase, where strong density increase and profile effects are observed. Data from a 30-Hz, 10-spatial-channel Thomson scattering diagnostic [4] is used extensively to observe HHFW heating effects. This diagnostic provides profiles of the electron temperature, $T_{e}(R)$, and density, $n_{e}(R)$, against the equatorial major radius $R$. The line-integrated densities, $n_{e} l$, presented here are also obtained with Thomson scattering. The content of this paper pertains to the operation of the antenna at $\mathrm{k}_{/ /} \sim 14 \mathrm{~m}^{-1}$ and frequency of $30 \mathrm{MHz}$.

\section{HARDWARE}

The hardware implementation makes maximum use of the equipment recovered from TFTR [5]. The HHFW heating system on NSTX includes an antenna made of an array of 12 current elements, fed by six transmitters. The twelve current elements are interconnected with de-coupling loops, which permit arbitrary phasing between elements with equally distributed powers. This flexible configuration enables changes in the vacuum power spectrum in real time to provide heating or current drive. The system provides a $k_{/ /}$range of $4-14 \mathrm{~m}^{-1}$. More details can be found elsewhere [6].

\section{PLASMA HEATING DURING $I_{p}$ FLATTOP}

A set of experiments was conducted where the HHFW power was applied during the $I_{p}$ flattop. In these discharges, the radiated power is less than $10 \%$ of the HHFW power. In the first case, HHFW heating was applied to helium plasmas at a nominal toroidal field at the magnetic axis, $B_{T}$, of $0.29 \mathrm{~T}$, and $I_{p},=0.7$ MA. The antenna gap, $\delta_{A}$, was 5 $\mathrm{cm}$. We can see in Fig. 1, the time evolution of relevant parameters for two discharges: one

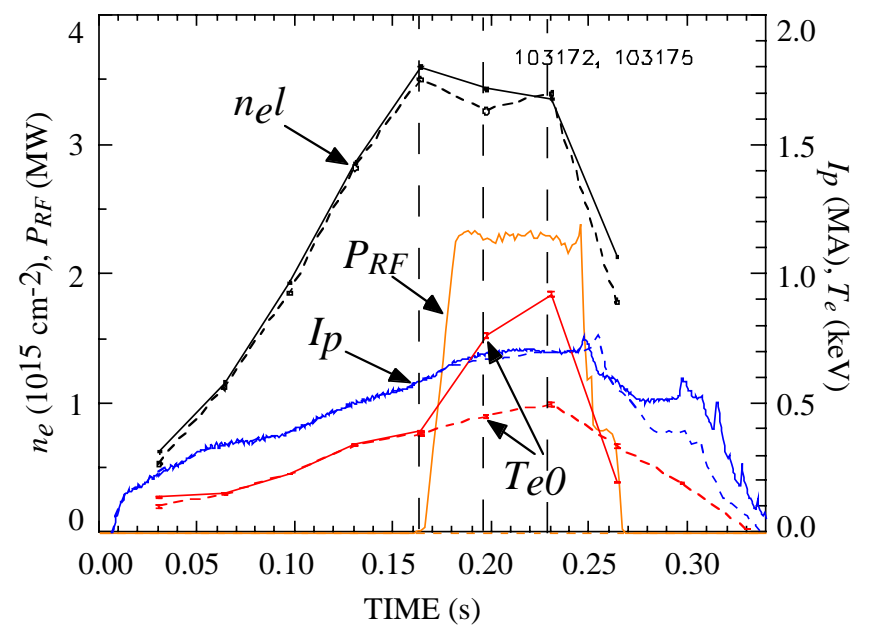

FIGURE 1: Evolution summary for HHFW (solid) and ohmic-only (dotted) in helium. 

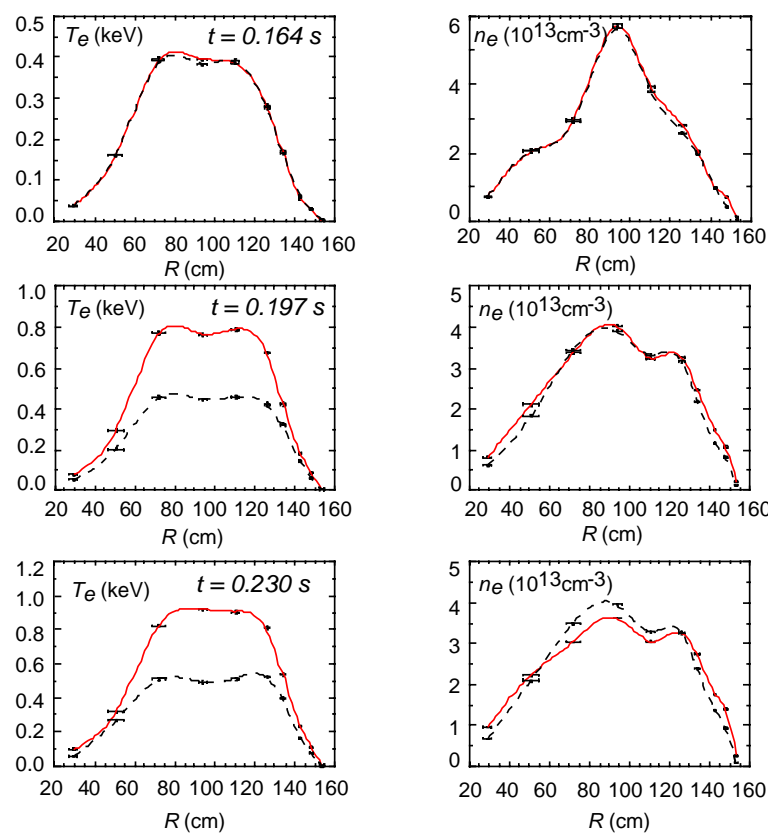

FIGURE 2: $T_{e}(R)$ and $n_{e}(R)$ profiles at $t=0.164$, 0.197 and $0.230 \mathrm{~s}$ during HHFW heating (solid) and ohmic-only (dotted) in helium plasma. with HHFW heating (solid line) and one ohmic-only reference discharge (dotted line). Until further notice, we will use this solid $v s$ dotted line convention. One can see that the plasma current and the line-integrated density, $n_{e} l$, are well matched. The 2.4MW HHFW heating pulse, which occurs during the $I_{p}$ flattop, nearly doubles the central electron temperature, $T_{e 0}$, when compared to the corresponding time point of the reference discharge. We can see in Fig. 2, $T_{e}(R)$ and $n_{e}(R)$ profiles for three time points indicated by dashed vertical markers in Fig. 1. In Fig. 2 top panel we see that at $t=0.164 \mathrm{~s} \mathrm{-}$ $10 \mathrm{~ms}$ before the HHFW heating onset $-T_{e}(R)$ and $n_{e}(R)$ of the HHFW and reference plasmas are essentially identical. The electron density profile is peaked. At $t=0.197 \mathrm{~s}$, middle panel,

we see that, with HHFW, $T_{e}(R)$ has increased in the core region to $0.8 \mathrm{keV}$. Both the HHFW and the reference plasmas have a flat $T_{e}(R)$ in the core region. Meanwhile the electron density profile, right, has changed shape - for the HHFW heated and the reference plasmas - compared to the previous time point. This $n_{e}(R)$ shape - with a "hump" at $R \approx 130 \mathrm{~cm}$ - is usually seen in presence of an $\mathrm{n} / \mathrm{m}=1 / 1$ mode. This mode is in fact observed for both the HHFW and ohmic-only discharges, on the ultra-soft $\mathrm{x}$ ray signal. Finally, bottom panel, $T_{e}$ reached $0.94 \mathrm{keV}$, at $t=0.230 \mathrm{~s}$, with a flat core

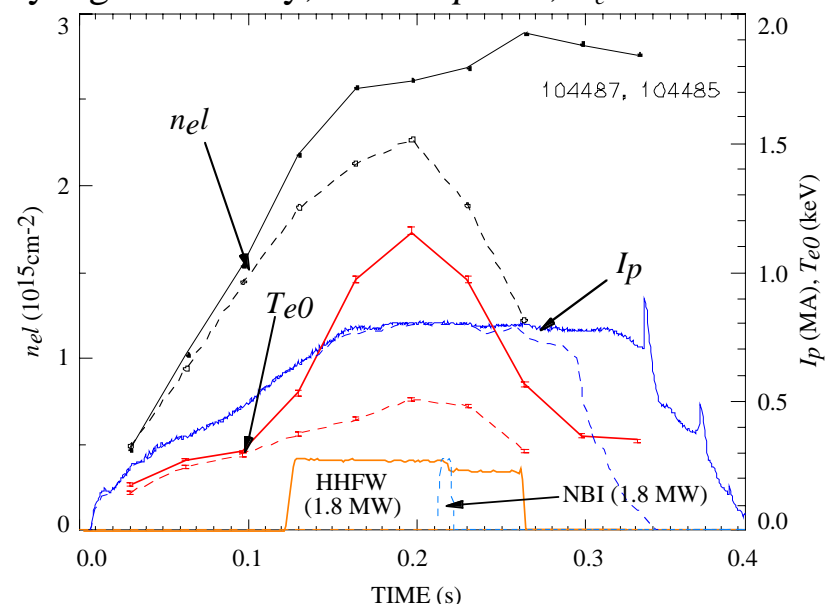

FIGURE 3: Evolution summary for HHFW (solid) and ohmic-only (dotted) in helium. profile. While the electron temperature increase occurs over a wide region of the plasma column, we note that the density profile remains essentially unchanged.

The above experiment was repeated in helium and deuterium in similar conditions, but in absence of the $\mathrm{m} / \mathrm{n}=1 / 1$ mode. Plasma parameters were $B_{T}=0.33$ $\mathrm{T}, I_{p}=800 \mathrm{kA}$ and $\delta_{A}=3 \mathrm{~cm}$. Different kinetic behaviors resulted from the application of HHFW power to helium and deuterium plasmas. We see in Fig. 3 a time-history comparison for 

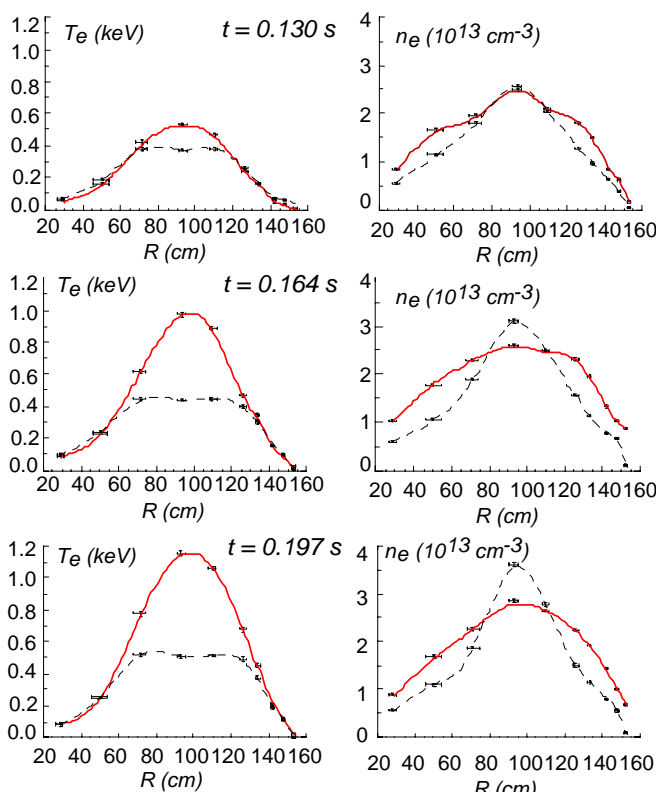

$104487-85$

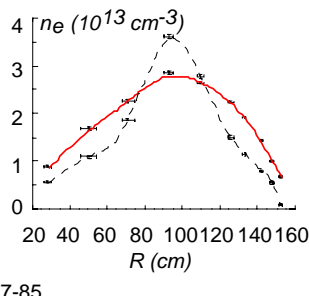

FIGURE 4: $T_{e}(R)$ and $n_{e}(R)$ profiles at $=$ $0.130,0.164$ and $0.197 \mathrm{~s}$ during HHFW heating (solid) and ohmic-only (dotted) in helium plasma.

helium plasma. The HHFW phase spans the 0.12-0.26 s interval at a power of 1.8 MW. Most of the HHFW power pulse occurs during the $I_{p}$ flattop. For the times of interest, the plasma current for the two discharges is essentially identical, reaching the $800-\mathrm{kA}$ flattop at $\approx 0.160 \mathrm{~s}$. At $t=0.097$ $\mathrm{s}$, the last Thomson scattering time point before HHFW onset, the central electron temperature, $T_{e 0}$, for both discharges is the same. But for the following time points, we see that, with $\mathrm{HHFW}, T_{e 0}$ increases faster than for the reference plasma, reaching 1.15 $\mathrm{keV}$ at $0.197 \mathrm{~s}$, more than twice the value for the companion discharge. During the same interval, $n_{e} l$ increases faster with HHFW, exceeding the reference $n_{e} l$ by $\leq$ $15 \%$. Note that for the purpose of $T_{i}$ documentation, a short neutral beam pulse was applied to the reference plasmas over the interval 0.21-0.22 s. We see in Fig. $4, T_{e}(R)$ and $n_{e}(R)$ profiles at three successive Thomson scattering time points after the HHFW turn-on, but before the neutral beam pulse. In top panel Fig. 4, we see that at $t=0.130 \mathrm{~s}-10 \mathrm{~ms}$ after the HHFW pulse onset $-\mathrm{a} T_{e}$ increase is already visible in the core region, relative to the reference plasma. To the right, we observe that the central density remains unchanged, but that "shoulders" are building up on the density profile. At $t=0.164 \mathrm{~s}$, middle panel, we see a strong central $T_{e}$ increase up to $1 \mathrm{keV}$, while the

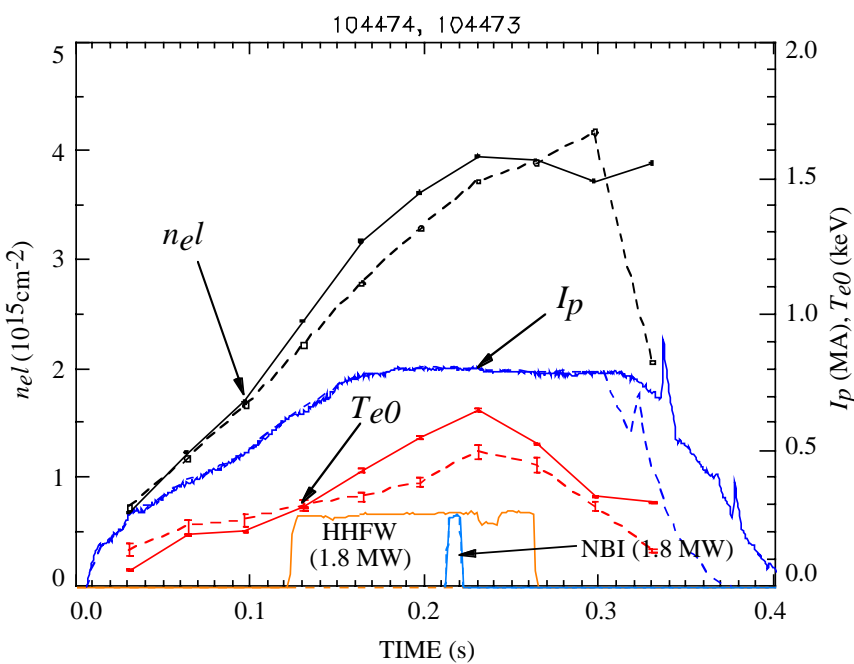

FIGURE 5: Evolution summary for HHFW (solid) and ohmic-only (dotted) in deuterium. central density falls and the shoulders expand out, raising the edge density. Although the electron density has increased at the shoulder locations, one does not see a corresponding decrease of the electron temperature. The flat central $T_{e}(R)$ of the reference discharge hovers slightly above $0.4 \mathrm{keV}$ with a broad profile, while $n_{e}(R)$ has entered a peaking, sequence. At $t=0.197 \mathrm{~s}$, bottom panel, the electron temperature reaches $1.15 \mathrm{keV}$, with a broad central region of $T_{e}(R)$ enhancement over the 

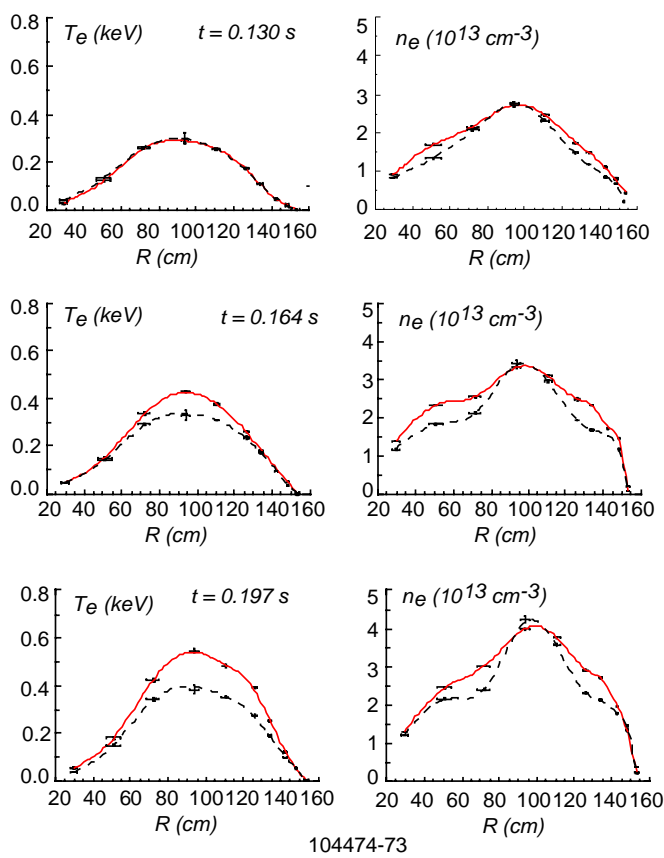

FIGURE 6: $T_{e}(R)$ and $n_{e}(R)$ profiles at $t=$ $0.130,0.164$ and $0.197 \mathrm{~s}$ during HHFW heating (solid) and ohmic-only (dotted) in deuterium plasma.

reference profile. On bottom right, we see that the density profiles have different shapes, with the HHFW having a "parabolic" shape, while the ohmic-only plasma exhibits a peaked $n_{e}(R)$ profile.

Figure 5 shows the corresponding timeevolution summary plot for deuterium plasma. The experimental conditions are the same as for the helium plasma, except for a slightly larger antenna gap, $\delta_{A}=4 \mathrm{~cm}$. The HHFW power is again $1.8 \mathrm{MW}$ and, as above, the plasma current for both discharges overlays well throughout the times of interest. Both the HHFW and reference discharges have a $10-\mathrm{ms}$ neutral beam pulse starting at $0.21 \mathrm{~s}$ for $T_{i}$ documentation. The lineintegrated density traces diverge slightly after HHFW turn-on, with that of the HHFW

plasma being larger by $<10 \%$. Looking at times before the start of neutral beam injection, we see a more modest $T_{e o}$ increase of order $\approx 40 \%$ to $\approx 0.55 \mathrm{keV}$, at $t=0.197 \mathrm{~s}$, compared to the helium plasma. Before describing the profiles effects for the two plasmas just discussed, it is worth mentioning that with HHFW power of $2.4 \mathrm{MW}, T_{e o}$ reached $0.625 \mathrm{keV}$, a $60 \% T_{e o}$ increase. Figure 6 shows the $T_{e}(R)$ and $n_{e}(R)$ profiles for times during HHFW, but before neutral beam pulses for the deuterium plasmas shown in Fig.5. Contrary to what was observed with

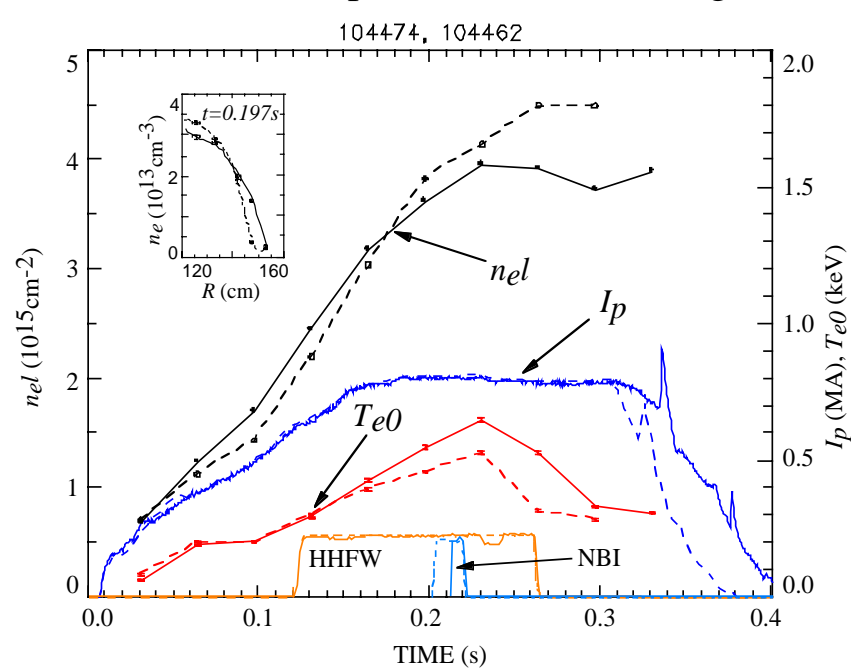

FIGURE 7: Evolution summary for two $\mathrm{D}_{2}$ plasmas. The plasma closer to the antenna, $\delta_{A}=4 \mathrm{~cm}$, has better heating than plasma with $\delta_{A}=9 \mathrm{~cm}$. Details of $n_{e}(R)$ at $t=0.197 \mathrm{~s}$ shown helium, no heating can be seen at $t=0.130 \mathrm{~s}$, but we still can see the beginning of shoulder formation on $n_{e}(R)$. Later on at $t=0.164 \mathrm{~s}$, central $T_{e o}$ increase becomes apparent, with further development of the density shoulders. At $t=0.197 \mathrm{~s}$, the central temperature reaches $0.55 \mathrm{keV}$ and the central density shows a small decrease.

There is experimental evidence that edge density plays a role in the power coupling. We can see in Fig. 7 an overlay of evolution summary plots for two deuterium discharges with 


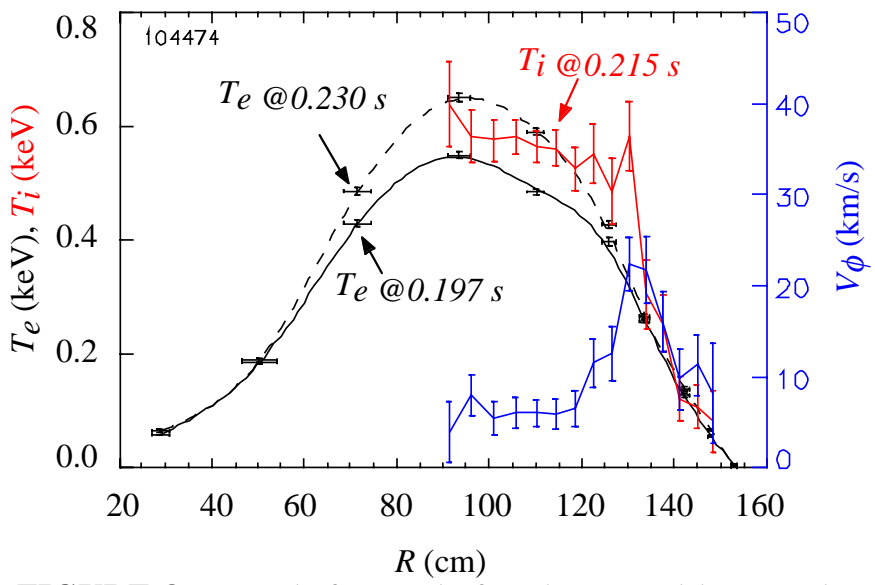

FIGURE 8: $T_{e}(R)$ before and after the neutral beam pulse. $T_{i}(R)$ toroidal velocity $V_{\phi}$ measured during the neutral beam matching HHFW heating power, but different major radius location. It can be seen that HHFW performs better for the plasma closer to the antenna (solid line) compared to the case where the plasma column is further out by about $5 \mathrm{~cm}$.

As mentioned earlier, short neutral beam pulses were used to measure $T_{i}(R)$ by charge exchange recombination spectroscopy using the "interim" CHERS system. This diagnostic measures the ion temperature and toroidal

velocity of the carbon impurity. We can see in Fig. 8, $T_{e}(R)$ profiles taken just before and after the neutral beam pulse. One can see that the latter $T_{e}(R)$ profile is higher by about $100 \mathrm{eV}$ as a result of the additional auxiliary power from the neutral beam pulse. It can be seen that within the uncertainty associated with the neutral beam pulse perturbation, the thermal ions and electrons have the same temperature in the core and the edge region. Similar measurements made in discharges without HHFW heating bring the same conclusion, although with the difference that the temperatures are lower. The ion temperature increment, during HHFW heating, is of the order of the electron temperature increase. This experimental observation is consistent with the electron-ion thermal equilibration time, which for these discharges is $10-15 \mathrm{~ms}$.

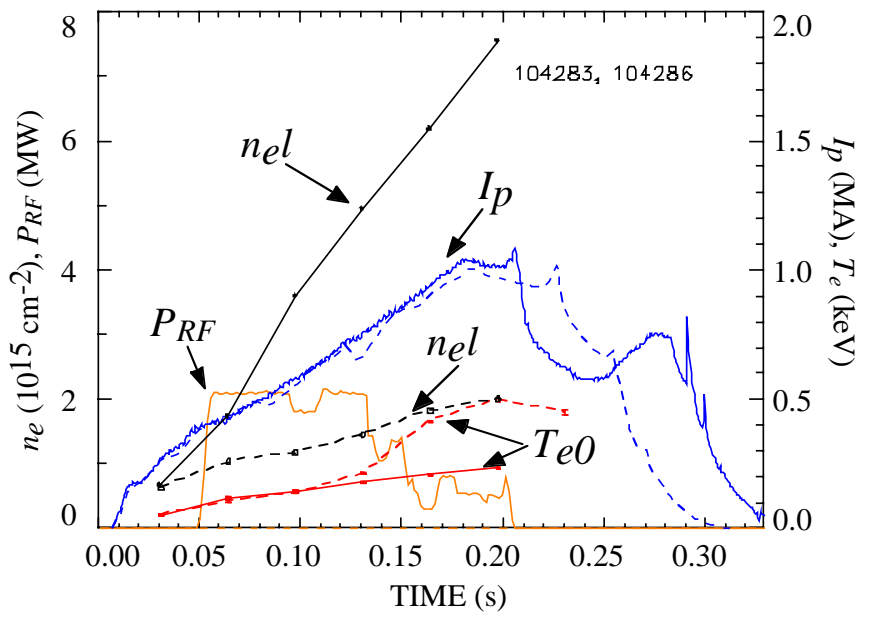

FIGURE 9: Time evolution of plasma with HHFW power applied during $I_{p}$ ramp-up (solid line) and reference plasma (dotted line).
HHFW HEATING DURING $I_{p}$ RAMP-UP

Since earlier HHFW heating results had shown that power could be coupled to lowtemperature plasmas, it was decided to attempt HHFW heating during the $I_{p}$ ramp-up in hopes of slowing down the plasma current diffusion and improving the MHD stability. These discharges were generated at at 1-MA plasma current, a toroidal field of $0.3 \mathrm{~T}$, in deuterium and with an antenna gap of $\approx 12 \mathrm{~cm}$. This mode of operation was 


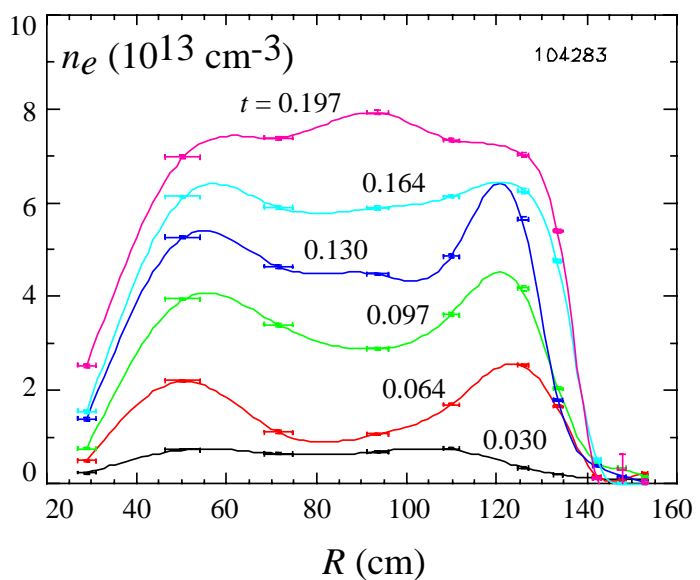

FIGURE 10: HHFW heating during $I_{p}$ rampup Density profiles before $(t=0.03 \mathrm{~s})$ and at 5 times during HHFW power pulse. conducive to a regime where the $n_{e}(R)$ profile undergoes substantial changes, while $T_{e}$ increases slowly. We can see in Fig. 9 a time evolution summary for such a discharge, which is shown in solid lines. A reference, ohmic-only discharge is shown in dotted lines. This operational scenario resulted in $n_{e} l$ values reaching $7.8 \times 10^{15} \mathrm{~cm}^{-2}$, a nearly fourfold increase over the reference plasma. Magnetic measurements show an increase of nearly $50 \%$ of the stored energy. The Thomson scattering density profiles are shown in Fig. 10, with five time points during the HHFW power pulse. An inverted density profile shape is maintained for times, $t=0.064-0.164 \mathrm{~s}$. The center

fills in by $t=0.197 \mathrm{~s}$. The density evolves into a flat profile with large edge gradients. The central density reaches $8 \times 10^{13} \mathrm{~cm}^{-3}$. Bolometric measurements show a hollow radiation profile, similar to $n_{e}(R)$, with a radiative power $\geq 25 \%$ of HHFW power.

\section{POWER DEPOSITION}

Theoretical models predict single pass absorption caused by a combination of Landau damping and magnetic pumping. We can see in Fig. 11, the power per unit volume predicted by the ray tracing code HPRT [7] and the METS [8] full wave 1$\mathrm{D}$ code. Both calculations predict a power deposition broadly localized mainly outside of the plasma core. Since volume integration of these profiles favors the outer region, one would expect most of the HHFW power to be deposited outside of the plasma core. These calculations correspond to application of HHFW power during the $I_{p}$ flattop in helium.

\section{CONCLUSION}

HHFW electron heating has been observed in helium and deuterium plasmas. The heating effectiveness varies. For a HHFW power of $1.8 \mathrm{MW}$, we observe strong heating in helium plasmas, which can more than double the target
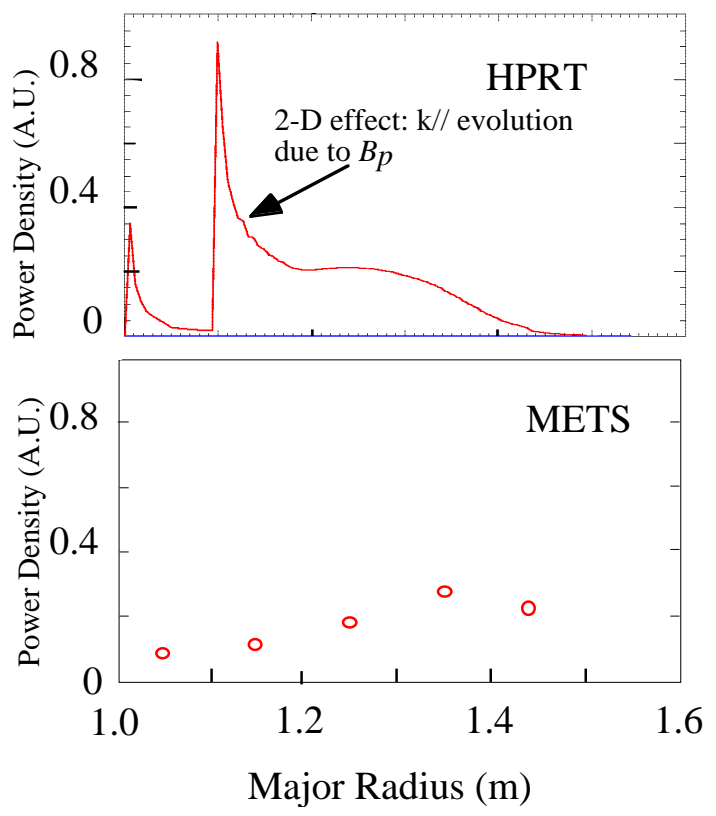

FIGURE 11: Power deposition predictions obtained from ray-tracing calculation (HPRT) and full-wave 1-D computation (METS). 
plasma temperature. Repeating these experiments in deuterium plasma results in less electron heating, with a $T_{e}$ increase of order $40 \%$. A definitive explanation for the lower effectiveness observed in deuterium plasmas would require more work.

There is circumstantial experimental evidence that heating is more efficient with higher edge density, although a thorough investigation has not been done yet. A possible mechanism consistent with this observation has been proposed in terms of wave scattering by edge turbulence [9].

The heating results in presence of $\mathrm{n} / \mathrm{m}=1 / 1$ MHD mode differ from when such a mode is absent. (Bearing in mid that the MHD vs no-MHD data sets are not a perfect match.) In presence of the $\mathrm{n} / \mathrm{m}=1 / 1$ mode, the $n_{e}(R)$ profile is essentially unaffected by the application of HHFW power. A near doubling of the core $T_{e}$ is observed, with the core region featuring a flat $T_{e}(R)$ profile. In MHD quiescent discharges, HHFW power more than doubles the core $T_{e}$, generating a peaked core $T_{e}(R)$ profile. However, we also observe a progressive modification of the density profile. The occurrence of density profile shoulders in the mid minor radius region eventually depresses the central density and increases the edge density measured by Thomson scattering. The plasma radiation losses remain lower than $10 \%$ of the applied HHFW power. The experimental data suggest that more than simple heating in the sense of "temperature increase" occurs and that particle confinement and/or fuelling issues are also present.

These latter effects seem to take over the dynamic of the discharge in cases where the HHFW power is applied during the $I_{p}$ ramp-up phase, during which a large increase of the plasma density occurs, bringing the central density up to $8 \times 10^{13} \mathrm{~cm}^{-3}$. During this process, the plasma $n_{e}(R)$ profile develops large edge density gradients. For these plasmas, the plasma radiation losses are larger than $25 \%$ of the applied HHFW power. Nevertheless, even in presence of this enhanced radiation loss and large density increase, the electron temperature rises steadily, although at a rate lower than or equal to that of the reference discharge.

The METS wave solver code and the HPRT ray tracing code calculations indicate that the power deposition should be localized in the outer minor radius region on the low-field side. On the other hand, the electron temperature increase is observed to occur in the core region. Measurement of the power deposition profile would help elucidate whether the latter results are the reflection of transport effects, or of the actual HHFW power deposition being located in the core region.

1. S.M. Kaye, et al., Phys. Plasmas, 8 (2001) 1977

2. Ono, Phys. Plasmas 2 (1995) 4075

3. J. Menard et al. Phys. Plasmas 2 (1998) 2002

4. D. Johnson, et al., Rev. Sci. Instum. 70 (1999) 776-779

5. J. R. Wilson et al., RF Power in Plasmas, AIP Proc. 485, 1999, p. 168

6. D.W. Swain, poster B41 at this conference.

7. A. Rosenberg, poster B39 at this conference.

8..D.N. Smithe, et al., AIP Conf. Proc. 485 (1999) 349

9. M. Ono, poster A38 at this conference. 


\section{External Distribution}

Plasma Research Laboratory, Australian National University, Australia

Professor I.R. J ones, Flinders University, Australia

Professor J oão Canalle, Instituto de Fisica DEQ/IF - UERJ , Brazil

Mr. Gerson O. Ludwig, Instituto Nacional de Pesquisas, Brazil

Dr. P.H. Sakanaka, Instituto Fisica, Brazil

The Librarian, Culham Laboratory, England

Library, R61, Rutherford Appleton Laboratory, England

Mrs. S.A. Hutchinson, JET Library, England

Professor M.N. Bussac, Ecole Polytechnique, France

Librarian, Max-Planck-Institut für Plasmaphysik, Germany

J olan Moldvai, Reports Library, MTA KFKI-ATKI, Hungary

Dr. P. Kaw, Institute for Plasma Research, India

Ms. P.J . Pathak, Librarian, Insitute for Plasma Research, India

Ms. Clelia De Palo, Associazione EURATOM-ENEA, I taly

Dr. G. Grosso, Instituto di Fisica del Plasma, Italy

Librarian, Naka Fusion Research Establishment, J AERI, J apan

Library, Plasma Physics Laboratory, Kyoto University, J apan

Research Information Center, National Institute for Fusion Science, J apan

Dr. O. Mitarai, Kyushu Tokai University, J apan

Library, Academia Sinica, Institute of Plasma Physics, People's Republic of China

Shih-Tung Tsai, Institute of Physics, Chinese Academy of Sciences, People's Republic of China

Dr. S. Mirnov, TRINITI, Troitsk, Russian Federation, Russia

Dr. V.S. Strelkov, Kurchatov Institute, Russian Federation, Russia

Professor Peter Lukac, Katedra Fyziky Plazmy MFF UK, Mlynska dolina F-2, Komenskeho Univerzita, SK-842 15 Bratislava, Slovakia

Dr. G.S. Lee, Korea Basic Science Institute, South Korea

Mr. Dennis Bruggink, Fusion Library, University of Wisconsin, USA

Institute for Plasma Research, University of Maryland, USA

Librarian, Fusion Energy Division, Oak Ridge National Laboratory, USA

Librarian, Institute of Fusion Studies, University of Texas, USA

Librarian, Magnetic Fusion Program, Lawrence Livermore National Laboratory, USA

Library, General Atomics, USA

Plasma Physics Group, Fusion Energy Research Program, University of California at San Diego, USA

Plasma Physics Library, Columbia University, USA

Alkesh Punjabi, Center for Fusion Research and Training, Hampton University, USA

Dr. W.M. Stacey, Fusion Research Center, Georgia Institute of Technology, USA

Dr. J ohn Willis, U.S. Department of Energy, Office of Fusion Energy Sciences, USA

Mr. Paul H. Wright, Indianapolis, Indiana, USA 
The Princeton Plasma Physics Laboratory is operated by Princeton University under contract with the U.S. Department of Energy.

\author{
Information Services \\ Princeton Plasma Physics Laboratory \\ P.O. Box 451 \\ Princeton, NJ 08543
}

Phone: 609-243-2750

Fax: 609-243-2751

e-mail: pppl_info@pppl.gov

Internet Address: http://www.pppl.gov 